\title{
Utilitarian Value of Selected Mechanical Strength Tests for A Lightweight Floor Construction with A Heating Coil
}

\author{
Jacek Karpiesiuk* \\ Bialystok University of Technology, Poland \\ *Corresponding author: Jacek Karpiesiuk, Bialystok University of Technology, Government Building Expert in construction and \\ building specialties, Member of the Polish Chamber of Civil Engineers, Wiejska str. 45A, 15-351 Bialystok, Poland
}

\begin{abstract}
This method of Lightweight floor construction does not require the use of heavy concrete screeds. It consists of a layer of hard thermal insulation on which the tile flooring is directly mounted, usingan adhesive mortar reinforced with a glass fiber mesh. This article summarizes the current results of the strength tests of this radiator model with XPS thermal insulation for bending, compression and point compression with a variety of constructional models. Application in all tests of various types and structures of insulating panels, with the use of glass fiber mesh and without it, allowed us to check and compare the most important strength parameters with different variants. At the same time, the principle of accepting materials that produce results guaranteeing the quality, durability and optimal price of the lightweight floor model with the use of a heating coil was followed.
\end{abstract}

Keywords: Compressive strength; Bending strength; Lightweight radiant heater; Cement adhesive

\section{Introduction}

In 2016 experimental studies on heat flux density and thermal inertia of light radiant heaters, described in [1] and [2], were completed. At the turn of 2016/2017, static shear strength, peel force, pull-off strength, shearing tests, absorbability and frost resistance tests were carried out on insulated EPS polystyrene insulation boards and extruded waffle type XPS with dissipating elements, using polyurethane adhesive [3]. This article describes compressive and bending strength in construction consisting of porcelain tiles, mounted to thermal insulation EPS or XPS through cement adhesive C2S1, both with and without the use of embedded glass fiber mesh. The latest tests on the strength of this radiator heater with XPS thermal insulation for bending, compression and point compression, with or without a glass fiber mesh, and with the use of PE/RT/Al/PE/RT PVC heating pipe with a diameter of $16 \times 2 \mathrm{~mm}$, or without it, was made at the Białystok University of Technology.

\section{Description of the measurement stand and research} methodology

The tests were carried out in the laboratory at the Białystok University of Technology. The research included bending strength, compression and point compression of samples in different variants, using the XPS300 insulating board, a Synthos waffle.
Bending strength was tested on the model of the size $45 \mathrm{~mm}$ (width) $\mathrm{x} 300 \mathrm{~mm}$ (length) $\mathrm{x} 50 \mathrm{~mm}$ (height) with tile, and dimensions $45 \mathrm{~mm}$ (width)x300mm(length) $\mathrm{x} 42 \mathrm{~mm}$ (height) without tiles. For bending, we used steel support set with surface $40 \times 45 \mathrm{~mm}$ and axial spacing of $220 \mathrm{~mm}$, and steel pressing stamp of $35 \times 47 \mathrm{~mm}$, all for 10 models. The first five models were tested with a glass fiber mesh $335 \mathrm{~g} / \mathrm{m} 2$, embedded in the cement mortar as follow:

1. XPS300 with pipe / Sika Ceram 255 / tile,

2. XPS300 only / Sika Ceram 255 / tile,

3. XPS300 with a groove without pipe / Sika Ceram 255 / tile,

4. XPS300 with pipe / Sika Ceram 255 / no tile,

5. XPS300 only / Sika Ceram 255 / no tile,

The same systems as above were tested but without the use of a mesh.

Compressive strength and point compression were tested on a model with dimension $80 \mathrm{~mm}$ (width) x $100 \mathrm{~mm}$ (length) x $50 \mathrm{~mm}$ (height) with tile and $80 \mathrm{~mm}$ (width) x $100 \mathrm{~mm}$ (length) $\times 42 \mathrm{~mm}$ (height) without tiles, using speed pressure of $4 \mathrm{~mm} /$ minute. In 
the compression test, a pressing and supporting steel stamp with a circular surface larger than the surface of the samples was used, and in the point compression test $20 \times 20 \mathrm{~mm}$ steel stamp was used. The following sample models were tested:

1. XPS Synthos 300 / Sika Ceram 255 with a mesh of 335g/ $\mathrm{m}^{2} /$ tile
2. XPS Synthos 300 / Sika Ceram 255 without a mesh of $335 \mathrm{~g} / \mathrm{m}^{2} /$ tile

3. XPS Synthos 300 / Sika Ceram 255 with a mesh of 335g/ $\mathrm{m}^{2} /$ no tile

The test stand and tooling are shown in Figure 1-4.

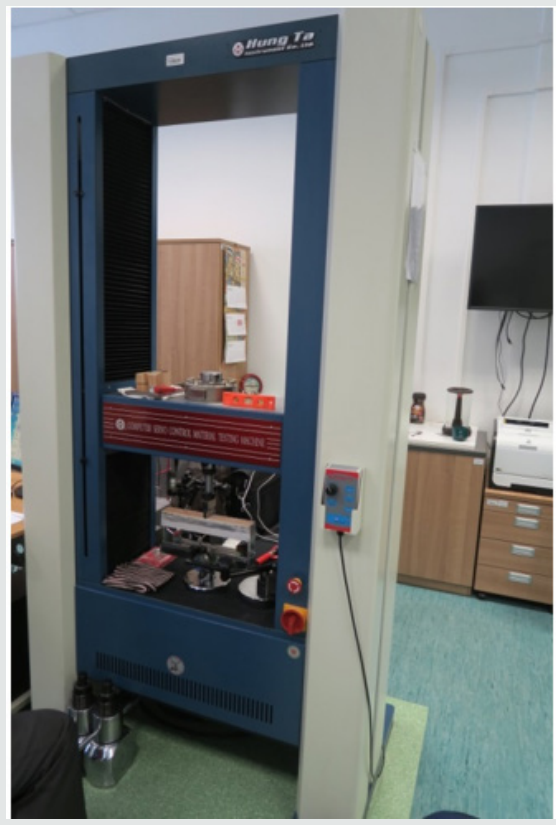

Figure 1: Measuring stand of Hung Ta Instrument Co. Ltd to test the bending and compression strength.

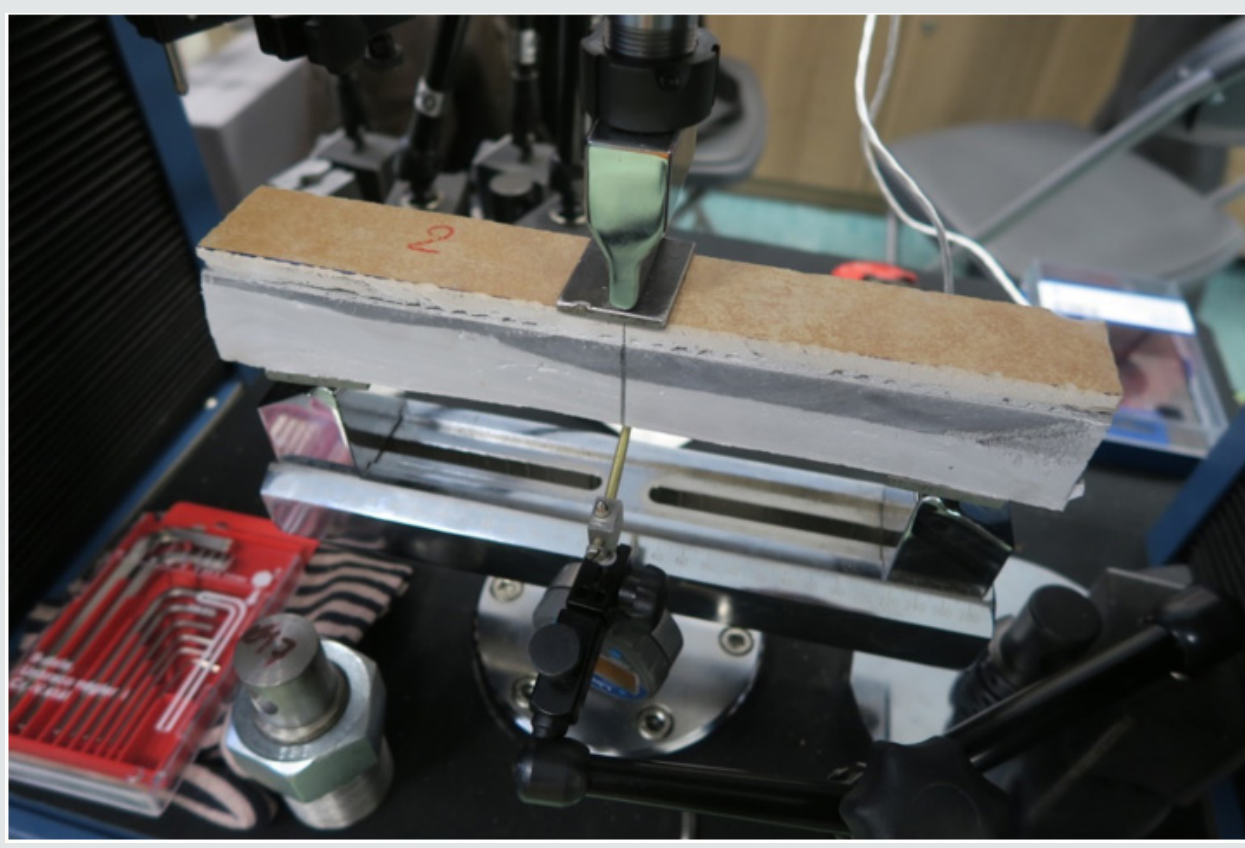

Figure 2: Tooling to measure bending strength. 


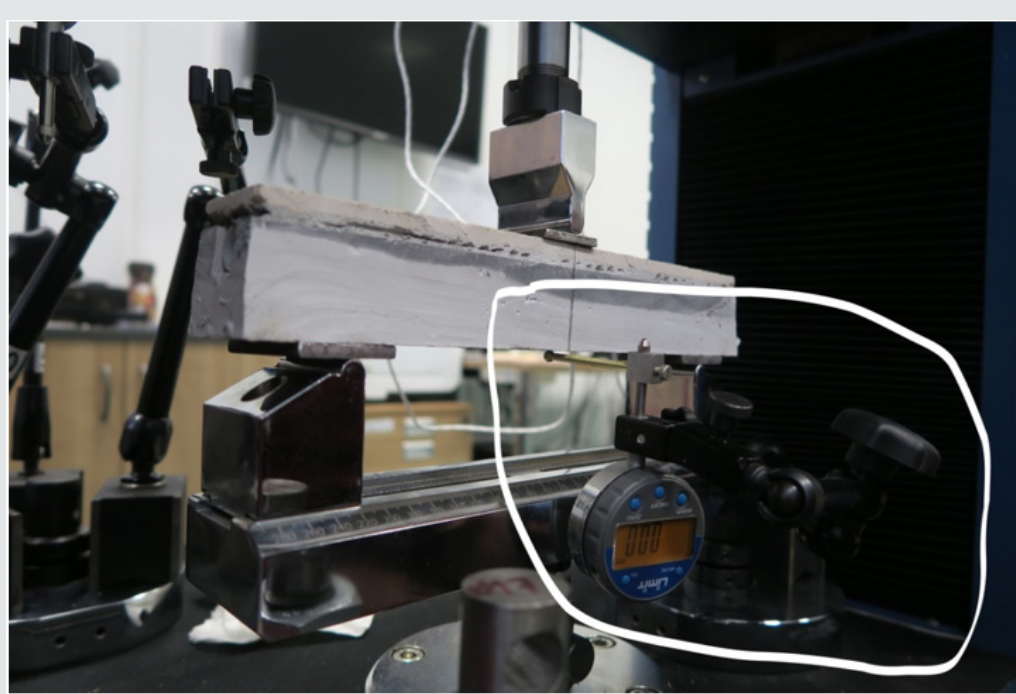

Figure 3: Digital indicator for measurement of bending Limit Company (marked in the border).

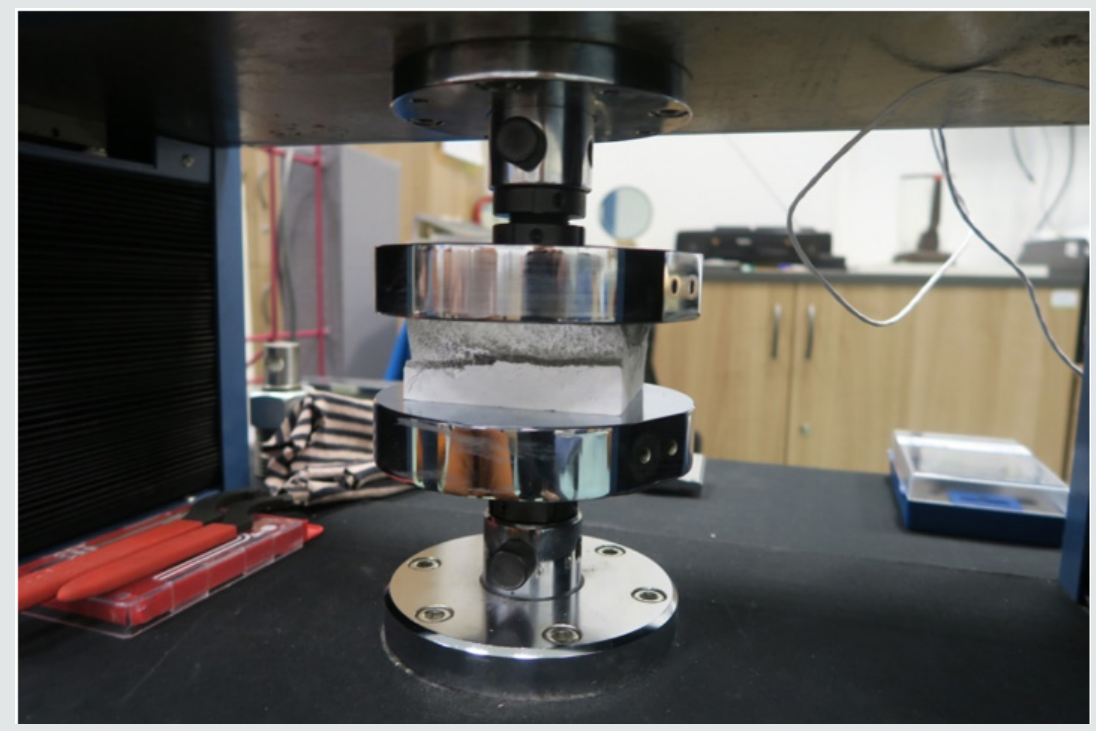

Figure 4: Tooling for measuring compressive strength.

\section{Measurements}

Maximum stresses causing destruction of samples and their smallest deflections when testing bending strength $\mathrm{Z}$, compression $\mathrm{S}$ and point compression $\mathrm{P}$ of a radiant heating model, made of thermal insulation from waffles XPS, according to the construction described in item 2 of this article, is shown in Table 1 . Value the $Z$, $\mathrm{S}$ and $\mathrm{P}$ strengths of the lightweight floor with the tiles are given under operating conditions (30 days from sample preparation).

Table 1: Results of bending, surface, and point compression tests of a lightweight floor made on XPS insulation.

\begin{tabular}{|c|c|c|c|c|c|c|}
\hline $\begin{array}{l}\text { The lowest deflection at max. } \\
\text { forces after } 30 \text { days }\end{array}$ & \multicolumn{3}{|c|}{ With Mesh } & \multicolumn{3}{|c|}{ Without Mesh } \\
\hline bonding 7 & with pipe & only XPS & without pipe & with pipe & only XPS & without pipe \\
\hline deflection $[\mathrm{mm}]$ force $[\mathrm{kN}]$ & $\begin{array}{l}10.1 \\
1.09\end{array}$ & $\begin{array}{l}11.62 \\
1.06\end{array}$ & $\begin{array}{c}12 \\
0.88\end{array}$ & $\begin{array}{r}9.8 \\
0.51\end{array}$ & $\begin{array}{l}8.9 \\
0.37\end{array}$ & $\begin{array}{c}11 \\
0.54\end{array}$ \\
\hline $\begin{array}{l}\text { surface compression S } \\
\text { deflection }[\mathrm{mm}] \\
\text { force }[\mathrm{kN}]\end{array}$ & \multicolumn{3}{|c|}{$\begin{array}{c}1.4 \\
3.18\end{array}$} & \multicolumn{3}{|c|}{$\begin{array}{l}1.8 \\
3.1\end{array}$} \\
\hline $\begin{array}{l}\text { point compression P - } \\
\text { (stamp } 2 \times 2 \mathrm{~cm} \text { ) } \\
\text { deflection }[\mathrm{mm}] \\
\text { force }[\mathrm{kN}]\end{array}$ & \multicolumn{3}{|c|}{2.9} & \multicolumn{3}{|c|}{2.37} \\
\hline
\end{tabular}




\section{Analysis of Results}

This article closes the cycle of basic tests of mechanical strength over the so-called light-radiant heater in which no type of screed occurs. The aim of the experiments was to determine the possibility of installing this heater in accordance with Article 5.1 of the Construction Polish Law [4]. The model of this radiant heater consists of a thermal insulation layer with grooves in which heating pipes are placed. A coil is inserted into the grooves, and all floor surface is covered with a cement adhesive in a system without metal diffusion plates or polyurethane glue with these metal plates. Adhesives, and their reinforcement in the form of fiberglass mesh, were adopted, which according to the technical description of manufacturers can be used in such radiant heaters on difficult substrates.

Various lightweight heater designs were investigated, using a hard, easy to process thermal insulation with a minimum compressive stress of $200 \mathrm{kPa}$ (EPS) and $300 \mathrm{kPa}$ (XPS), with a bending strength of minimum $250 \mathrm{kPa}$ (EPS) and $300 \mathrm{kPa}$ (XPS), according to the Declaration of Properties Utility given by manufacturers and adequately guaranteed standards [5] and [6]. To reinforce the cement adhesive layer, a glass fiber mesh was used on which the most popular type of flooring - tile (stone) was laid. We can use it with underfloor heating or possibly a wall covering in wet rooms. This article summarizes new experiments that were carried out on samples of the entire heating model during bending, surface compression and point compression (puncture), in accordance with the construction described in point. 2., under operating conditions.

The maximum bending force resulting in the destruction of the model with the mesh was on average about $1.1 \mathrm{kN}$, and without it about $0.48 \mathrm{kN}$ in different variants - with a mounted coil, without it or with an empty groove. At the same time, this gives a result at least two times better for the radiator construction with mesh reinforcement. The use of a mesh is not so important in compressive strength tests and puncture. The maximum compressive force was $3 \mathrm{kN}$ on average, regardless of whether the radiator was reinforced with mesh or not, while the puncture force in the structure with the mesh was on average $3 \mathrm{kN}$, and without it $2.33 \mathrm{kN}$.

Destruction of the samples during the bending strength test occurred at the lowest deflection (elongation) of $10.1 \mathrm{~mm}$ (sample with mesh) and $8.9 \mathrm{~mm}$ (sample without mesh) with the axial spacing of supports $220 \mathrm{~mm}$. According to the standard [7] for concrete structures calculation of deflections are not necessary if the deflection arrow of a beam, plate or bracket under load exceeds $1 / 250$ of the span. In the previous Polish standard [8] for beams, slabs and flat roofs, the limit values of deflections could not exceed $1 / 200$ or $30 \mathrm{~mm}$ with the construction spans $6-7,5 \mathrm{~m}$. In accordance with the above standards, the deflections of the main building structures referring to the tested samples in which the spacing of supports was $220 \mathrm{~mm}$ can be maximum $220 \mathrm{~mm} / 250=0.9 \mathrm{~mm}$ or $220 \mathrm{~mm} / 200=1.1 \mathrm{~mm}$. Deflections in the tests amounted to at least 10 times more, from $9 \mathrm{~mm}$ to even $32 \mathrm{~mm}$. In the case of wooden structures described in the standard [9], the limit deflection arrow is the higest for beams based on 2 supports - 1/150 or for the bracket $-1 / 75$, including the inverse deflection. It follows that the maximum deflections in relation to our samples can be $220 \mathrm{~mm} / 150$ $=1.47 \mathrm{~mm}$ or $220 \mathrm{~mm} / 75=2.93 \mathrm{~mm}$. It is still 3 times lower than the results achieved in the tested samples from $8.9 \mathrm{~mm}$ upwards. This means that the construction of the light floor is very flexible and is able to bending more, without cracks than all acceptable standard deflections in both, concrete and wooden structures.

The maximum compressive force was not less than $2.6 \mathrm{kN}$, and its average value in operating conditions after 30 days was $3.1 \mathrm{kN}$. This gives us, per $\mathrm{m}^{2}$, a strength of not less than $325 \mathrm{kN} / \mathrm{m}^{2}$. At very high compressive force, the samples of the lightweight radiant heater were not destroyed, they were subject only to progressive flattening (deflection). This means there is great resistance of such a radiant heater to any variable payloads found in construction works, including those subjected to dynamic loads. The tested values confirm the compression strength of XPS 300 insulation boards, declared by manufacturers, amounting $\geq 300 \mathrm{kN} / \mathrm{m}^{2}$, in accordance with the standard [6]. This result is very high when we want to compare it to what is projected on the basis of the standard [10]. Utilitarian loads for the rooms, bedrooms of residential buildings and waiting rooms in hospitals, bedrooms in hotels, kitchens and toilets, are only $2 \mathrm{kN} / \mathrm{m}^{2}$, or rooms with tables (in schools, cafes, restaurants, canteens, reading rooms, receptions, waiting rooms) $3 \mathrm{kN} / \mathrm{m}^{2}$, and the maximum included in this standard with the area generally accessible to the crowd (in public buildings, concert halls, sports halls with stands, terraces, access points and railway platforms) amount to $7.5 \mathrm{kN} / \mathrm{m}^{2}$. The maximum tested force under point compression with an area pressure of $4 \mathrm{~cm}^{2}$ imitating the legs of a chair or table using a glass fiber mesh was not less than $2.9 \mathrm{kN}$.

\section{Conclusion}

The bending strength of a radiant heater without screeds is made higher by using cement adhesives with a glass fiber mesh. As already pointed out in an earlier article [11], the cost of the fiber mesh does not have a significant impact on the price of the entire lightweight radiant heater.

The lightweight, not require screed floor is flexible enough to meet the standard requirements regarding the serviceability limit state at the deflections of concrete structures and wooden structures. It can be dedicated to all types of construction objects, both residential and sacral, sports, and other public utilities, and in industrial buildings with storage and production areas, depending on the loads determined to take into account the intended use and equipment installed. In the case when it can be expected that resonance effects will occur as a result of synchronous, rhythmic movement of people (eg dances, jumps), it is recommended that the calculation model be determined on the basis of a special dynamic analysis contained in [10].

Assuming placing on the floor a table with 4 legs, each with an area of $4 \mathrm{~cm}^{2}$, the tested heater is able to transfer the maximum load of over $11 \mathrm{kN}$. During work, when the floor is not yet laid, the 
maximum point load on the surface of $4 \mathrm{~cm}^{2}$ should not exceed $1 \mathrm{kN}$. Under normal conditions of use, there are no such heavy loads.

This article closes the cycle of basic strength tests of a light, thin radiant heater without screeds, and confirms the possibility of its use in all construction objects. I suggest adding to the current experiments new adhesion tests of type C2S2 cement adhesive, with 2 times greater deformability. This will allow a comparison with the results of the tested polyurethane adhesive strength, and give an answer to the question of whether it will be possible to use it outside of buildings, in snow and ice protection systems.

\section{Acknowlegement}

The author of the article would like to thank Mrs. Anna Zakowicz and Mr. Tadeusz Chyzy from the Bialystok University of Technology for providing laboratories.

\section{References}

1. Zukowski M, Karpiesiuk P (2015) Instal, Experimental testing of the floor heating system - ultra flat 10(366): 38-41.

2. Karpiesiuk J, Chyzy T (2017) The results of experimental searching temperature distribution of the radiant heaters with lightweight construction without screeds. Rynek Instalacyjny 11(XXV): 45-50.
3. Karpiesiuk J, Chyzy T (2017) The results of selected interface strength of lightweight radiant heater with dissipating elements. Civil and Environmental Engineering 8(3): 123-132.

4. The Act of July 7, 1994 - Construction Polish Law. Dz. U. 1994 No. 89 item 414 with changes.

5. (2016) Thermal insulation products for buildings - Factory made expanded polystyrene (EPS) products - Specification. IrishStandard, EN 13163:2012+A2.

6. (2015) Thermal insulation products for buildings-Factory made products of extruded polystyrene foam (XPS)-Specification. EN 13164+A1.

7. EN 1992-1-1:2004+AC:2008, Eurocode 2: Design of concrete structures - Part 1-2: General rules -Structural fire design.

8. (2002) Konstrukcje betonowe, żelbetowe i sprężone. Obliczenia statyczne i projektowanie. PN-B-03264.

9. (2010) Eurocode 5: Design of timber structures - Part 1-1: General Common rules and rules for buildings. EN 1995-1-1.

10. (2004) Eurocode 1 Actions on structures - Part 1-1: General actions Densities, self-weight, imposed loads for buildings. EN 1991-1-1.

11. Karpiesiuk J, Chyzy T (2017) The results of selected strength tests of the adhesive layer of radiant heater with lightweight construction. Civil and Environmental Engineering 8(4): 165-171.

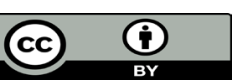

This work is licensed under Creative Commons Attribution 4.0 License

To Submit Your Article Click Here: Submit Article

DOI: 10.32474 /TCEIA.2019.03.000166

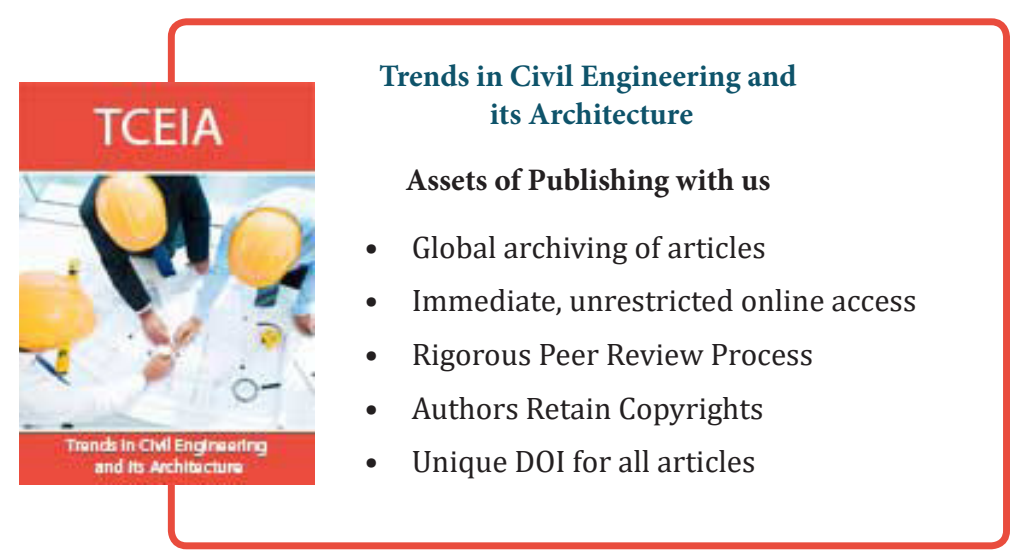

